\title{
The Effect of Psychological Capital and Organizational Support on Innovational Behavior and Silence Behavior of Technical Innovation Personnel in Strategic Emerging Industry
}

\author{
Yunchun Yu, Quan Liu \\ School of Government, Beijing Normal University, Beijing, China \\ Email: lucus@263.net, liuquanxue@126.com
}

Received 26 May 2016; accepted 17 June 2016; published 20 June 2016

Copyright (C) 2016 by authors and Scientific Research Publishing Inc.

This work is licensed under the Creative Commons Attribution International License (CC BY). http://creativecommons.org/licenses/by/4.0/

(c) (i) Open Access

\begin{abstract}
Chinese strategic emerging industry has been developed rapidly in recent years. As the important guarantee and intellectual support required in the development of this kind industry, enterprise technology innovation talents have become the most significant strength to promote the enterprise technology and industry progress. Therefore, how to guide and motivate their creativity ability at the most extent has come to be a vital scientific question. In order to search for the improvement path to such employees' innovation ability, the current study mainly investigated the effect of both psychological capital and organizational support on innovation and silence behavior within technical innovation personnel. Through the regression analysis of 350 questionnaires, our results showed that both psychological capital and organizational support had worthy negative effect on their silence behavior and positive effect on their innovation behavior, respectively; meanwhile, psychological capital and organizational support showed interaction effect to both innovation and silence behavior within technical innovation personnel. According to our results, in order to better motivate employees' innovation ability, corporations should take supportive policies and improve employees' psychological capital.
\end{abstract}

\section{Keywords}

Psychological Capital, Organizational Support, Innovational Behavior, Silence Behavior 


\section{Introduction}

In recent years, the strategic emerging industry has been developed rapidly. As an industry with characteristics such as knowledge and technology-intensive, less consumption of material resources, growth potential and good comprehensive benefits, strategic emerging industry is based on major technological breakthrough and development needs, and plays a significant leading role in the long-term economic and social development. The talent guarantee and intellectual support are required in the development of the industry, where the technical innovation personnel's complementary communication and innovation ability are the most important impelling force to promote its development. As a vital source of technological progress, innovative behavior refers to all the behaviors that show in individuals when generation of new ideals, composition, promotion and in the process of application [1]. Early studies paid special attention to the influence of individual characteristics on innovative behavior. After 1990s, researchers realized that the characteristics of individuals were more stable and difficult to change. While those mental states vulnerable to external influence such as motivation, feeling and emotion were easy to be excited, and played an important role to the performance of individual creativity. As a consequence, these mental state factors were gradually become the focus of attention by scholars. Zhao et al. believed that technical innovation personnel's innovation ability not only relied on physical capital and human capital as well as social capital, positive personal qualities were also needed, especially psychological capital [2].

Based on Trait Activation Theory, the predictive performance of individual characteristics to its behaviors is affected by the characteristics associated with situational factors. From the perspective of organization, Gu pointed out that organizational support was an important condition for employees' creativity, and perceived organizational support was an important perspective to indicate the relationship between supporting organization situation and innovative behavior of employees [3]. Therefore, it is of great important for the study of technology innovation talents' innovation ability that focusing on the individual characteristics and organizational context factors simultaneously as well as researching interactions on psychological capital and organizational support.

However, in the real organization, behavior of employee silence becomes an important factor that hinders technological development and employee innovation. Pinder \& Harlos pointed out that employee silence meant that when employees had the ability to improve the current situation of the organization, but they reserved the evaluation to all aspects of their organization, including behavioral, cognitive or emotional [4]. Employee silence brings great harm to both organization and individual. In terms of organization, it will affect the quality of decision-making and organizational performance; in terms of individual, it will reduce employee's job satisfaction, result in physical and mental anxiety [5] and decrease employee's enthusiasm and creativity [6].

Many scholars have actively explored the reasons for the formation of employee silence, such as individual character traits, leadership characteristics [7], the opportunity to communicate within the organization [8] etc. Studies have shown that it is critical to explore the ways to improve employees' silence for the staff creating the innovation atmosphere of technological innovation employees. Psychological capital is a positive state of mind in the process of individual growth and development. As a valuable individual resource to staffs, it will make employees have a positive attribution in the face of difficulties, and have an optimistic way to analyze problems as well as have a spirit of perseverance to overcome these difficulties. Psychological capital, to some extent, can alleviate silencing behavior of employees [9]. Combined with behavior elastic theory, employees' behavior will react differently under the influence of characteristics in distinct environments. Hence, the effect of employees' psychological capital on silence behavior will be influenced by external situations such as organizational support. However, current researches were focused on the formation mechanism of employee innovative and silence behavior just from one single perspective of organizational scenarios or individual characteristics, and there is no decent collaborative studies of both individual characteristics and organizational scenarios. At the same time, there are some scholars discussing the effect of organizational support and psychological capital on the employees' attitude and behavior, but the majority of those studies takes the psychological capital as a mediating variable. Moreover, researches on interaction of organization support and psychological capital are unclear, besides, it's still blank to use the technical innovation personnel as the study group.

Therefore, as a particular social group, the innovative technical talents were investigated in current study targets. Combined with the theory of characteristic excitation, we will investigate the key factor that influence their innovative and silence behavior, and analyze the effect of interaction of the organizational support and psychological capital on the innovative technical employee’s innovative and silence behavior deeply. Our research, on 
one hand, makes up for the deficiencies in the current theory; on the other hand, provides some guidance for improving the innovation capacity of enterprise technology innovation talents, thereby providing important talents support for the rapid development of the strategic emerging industries.

\section{Literature and Hypothesis}

Luthans defines psychological capital as a positive state of mind manifested in the process of individual growth and development. And the positive state of mind is expressed in four specific aspects made up of self-efficacy, optimism, hope and tenacity [10]. Studies have shown that good psychological capital have a positive impact on staff attitude [11]. Amabile's research showed that the positive emotions in work have a positive impact on innovative behavior of employees in organizations [12]. Considering the complexity and uncertainty of the innovation process, the innovative technical talents also need to have strong self-confidence and self-efficacy. Innovative behavior requires the innovative technical talents have steadfast driving force beyond the current challenges and setbacks, then to adapt the current changing environment. Scientific and technical personnel with high-level optimistic hope always attribute things to a positive interpretation. When faced with setbacks, they will actively look for new approaches and show more innovative behaviors. However, scientific and technical personnel with high level of confidence and brave believe their work ability, and don't afraid to take risks and responsibility, as well as dare to put forward their own innovative ideas and act more innovative behaviors [2].

Studies have shown that individuals with rich psychological capital will work better, more susceptible to organization and leadership awards, more likely to offer advice and suggestions for organization, and have lower level silent behavior. Employees with strong psychological capital dare to put forward their views, and also are able to withstand the trouble and setbacks they encountered after telling the truth; at the same time, they will take organizational things as their own business, do not care about personal gains and losses temporarily, and are willing to speak out the truth for organizational development. Combined with the Conservation of Resource Theory, if the individual has sufficient resources to mitigate and compensate for work stress and insecurity, it is possible to reduce or prevent negative results effectively. Thus, psychological capital is a positive state of mind manifested in the process of individual growth and development process. As a valuable individual resource, it can make individuals have a positive attribution in the face of difficulties, and an indomitable spirit to analyze and overcome problems with an upbeat manner. This can mitigate and compensate for the "speak" to employees of stress and insecurity to some extent, thereby reducing the generation of employees' silence behavior [9].

Based on the above descriptions, we hypothesis that:

H1a: Psychological capital can promote technical innovative personnel's innovative behavior.

H1b: Psychological capital can restrain technical innovative personnel's silence behavior.

Since Eisenberger et al. put forward the concept of organizational support, domestic and foreign scholars performed extensive research based on this concept. Organizational support refers to a general view of employees that how their organizations treat their contribution and interests [13]. Amabile paid long-term attention to the impact of organizational context on employees' creativity. He believes that the organizational support could make employees feel encouraged, respect and reward, thereby exhibiting strong innovation including emotional support, tool support of technical or task aspects and interpersonal support [12]. When employees perceive and receive creative support, work support and social support, they have the power of initiative and creative activities. Concurrently, Tan found that organizational support primarily affected staff innovative behavior in three aspects which were work support, interests concern and value identification [14]. Under the pressure of work requirements, Chen believes that compared with employees perceived low organizational support, those perceived higher organizational support were more prone to innovation behavior [15].

Bowen and Blackmon believe that if employees had a premonition that the views and opinions they put forward can get support from the other members of the organization, they tended to express their views. Otherwise, they would choose to be silence [16]. Therefore, only when employees perceive organizational support behavior, he dares to disclosure their own opinions or advices. Based on Social Exchange Theory, higher organizational support will make employees generate the responsibility to support the organization's objectives, and integrate their personal development objectives into organizational development goals and contribute themselves to organizational development goals. At the same time, employees will feel themselves having the duty to return the organization for giving them interests and opportunities. Once organization needs, they will offer help [17]. 
Edmondson found that if the team leader could establish the atmosphere in favor of "advices" within the organization, such as actively encouraging employees to express their views, creating incentives for reform and advice, providing psychological sense of security when employees make suggestions, then employees could give more attention confronted job problems and own courage to put forward their views [18]. So good organizational support will reduce the silent behavior of employees.

Based on the above descriptions, we hypothesis that:

H2a Organizational support can promote technical innovative personnel's innovative behavior.

H2b Organizational support can restrain technical innovative personnel's innovative behavior.

Based on Trait Activation Theory, the predictive power of individual characteristics to individual behavior is affected by situational factors associated with the characteristics. The more external situation is relevant to individual characteristics, the easier it is to stimulate individual characteristics and exhibit certain behaviors; and if the outside world situation is irrelevant or contrary to the individual characteristics, individual characteristics will be suppressed without showing a certain behavior. Since the expression of traits has inherent incentives for individuals, so people tend to focus on and find those situational factors associated with their own traits. Based on Trait Activation Theory, this paper argues that psychological capital and organizational support have interaction effect on employees' innovative and silence behavior. Organizations with strong atmosphere of organizational support can help to break employees' pessimism, reduce the pessimists' sense of isolation and promote the development of enhancing employees' optimism spirit, so as to stimulate their positive attitudes and behavior [13]. In this context, the staff with good psychological capital will be more active get into innovative behavior, avoid silence behavior, and actively offer advice and suggestions for the organization. Conversely, when employees feel less organizational support, even with good psychological capital, they still lack the motivation to stimulate their innovative behavior, leading to silent behavior.

Based on the above descriptions, we hypothesis that:

H3a: Psychological capital and organizational support have interaction effect on technological innovation personnel's innovative behavior.

$H 3 b$ : Psychological capital and organizational support have interaction effect on technological innovation personnel's silence behavior.

\section{Method}

\subsection{Sample}

In order to ensure the rigor of the study design, this study selected four enterprises of strategic emerging industries. They are mainly distributed in Beijing and Hebei region. Follow the principle of random sampling, the sample for the study was drawn from technology innovation employees in these enterprises. Out of the total 380 questionnaires distributed, 370 copies were returned and 350 of them were valid. In the 350 valid samples, 58.8\% male, $41.2 \%$ female; minimum education is secondary vocational school and below and the highest is doctor. Including specialist and below account for $12.2 \%, 29.3 \%$ of bachelor, 47.6\%of master, and doctors account for $10.3 \%$. The minimum work experience for 1 year and up to more than 10 years.

\subsection{Measuring}

Psychological capital: The paper uses the scale of psychological capital developed by Luthans [11]. This scale includes 4 dimensions and uses a 6 point Likert-style scale $(1=$ fully disagree, 2 = disagree, $3=$ a little disagree, 4 = a little agree, 5 = agree, $6=$ fully agree). The overall alpha was 0.87 .

Organizational support: The scale used in this paper was compiled by $\mathrm{Gu}$ [19], and from the organization, supervisor and colleagues' source of support to make item compilation. The measures were based on6 point Likert-style scale. Its overall alpha was 0.914 .

Innovative behavior: Innovation Behavior Scale developed by Zhou \& George [1]. This scale is single factor structure and there are 13 questions. The overall alpha was 0.856 .

Silence behavior: The paper uses the scale compiled by Zheng et al. [20]. It includes a total of 12items. The measures were based on6 point Likert-style scale and were three-dimensional factor structure. The overall alpha was 0.873 .

Control variable: Control variables include gender, educational background and work experience. Specifi- 
cally, gender: 1 = female, 2 = male; educational background: 1 = "secondary vocational school and under", 2 = "bachelor", 3 = "master", 4 = "doctor"; working experience: 1 = "1 years and under", 2 = "2 - 5 years", 3 = "6 9 years", $4=$ " $>10$ years".

\section{Results}

\subsection{Discrimination}

In the formal sample survey, we used confirmatory factor analysis to test variables' discriminant validity. We can see from Table 1, the 4 -factor model (base model) $\left(\chi^{2} / \mathrm{df}=2.68, \mathrm{CFI}=0.95\right.$, RMSEA $=0.04, \mathrm{TLI}=0.96$ ) is better than other nested model, and it has a good matching index. This means there is a good discriminant validity in the four variables of this study.

\subsection{Correlation Analysis of Variables}

Table 2 shows the means, standard deviation and Pearson correlation coefficient of variables. The mean and standard deviation don't have any abnormal phenomena. The results show that work experience has a significant role in promoting employees' psychological capital while a significant role in restraining employees' silence behavior. Employees' psychological capital has a negative effect on their silence behavior $(r=-0.203, p<0.001)$ while a positive effect on their innovative behavior $(r=0.660, \mathrm{p}<0.001)$. Organizational support has a significant positive effect on technical innovation employees' psychological capital $(r=0.365, p<0.001)$ and innovative behavior $(r=-0.145, p<0.01)$, meanwhile, a significant negative effect on their silence behavior $(r=0.590$, $\mathrm{p}<0.001)$.

\subsection{The Interaction Effect of Psychological Capital and Organizational Support on Technological Innovation Employees' Silence Behavior and Innovative Behavior}

This study further analyzed the influence of organizational support on technological innovation employees' silence behavior and innovative behavior, and the results are shown in Table 3. The VIF of model 1 - 6 is less than

Table 1. Confirmatory factor analysis.

\begin{tabular}{cccccc}
\hline Model & $\chi^{2} / \mathrm{df}$ & CFI & NFI & TLI & RMSEA \\
\hline Reference Model & 2.68 & 0.95 & 0.97 & 0.96 & 0.04 \\
Single-Factor Model & 6.89 & 0.56 & 0.57 & 0.59 & 0.37 \\
Two-factor model & 6.72 & 0.63 & 0.59 & 0.56 & 0.27 \\
Three-factor model & 6.17 & 0.73 & 0.71 & 0.69 & 0.19 \\
\hline
\end{tabular}

Table 2. Means, standard deviation, Pearson correlation coefficient of variables.

\begin{tabular}{|c|c|c|c|c|c|c|c|c|}
\hline & Mean & SD & 1 & 2 & 3 & 4 & 5 & 6 \\
\hline 1. Gender & 1.59 & 0.493 & & & & & & \\
\hline 2. Educational background & 2.58 & 0.857 & -0.045 & & & & & \\
\hline 3. Work experience & 2.14 & 1.053 & $-0.223^{* *}$ & $-0.141^{*}$ & & & & \\
\hline 4. Psychological capital & 3.85 & 1.064 & -0.025 & $0.120^{*}$ & 0.020 & & & \\
\hline 5. Organizational support & 3.31 & 1.092 & -0.100 & -0.024 & 0.001 & $0.365^{* * *}$ & & \\
\hline 6. Innovative behavior & 4.16 & 0.826 & 0.012 & $0.134^{*}$ & $-0.137^{*}$ & $0.660^{* * *}$ & $0.590^{* * *}$ & \\
\hline 7. Silence behavior & 1.53 & 0.363 & -0.084 & -0.085 & 0.090 & $-0.203^{* * * *}$ & $-0.145^{* *}$ & $-0.215^{* * *}$ \\
\hline
\end{tabular}

Notes: ${ }^{* * *} \mathrm{p}<0.001 ;{ }^{* *} \mathrm{p}<0.01 ;{ }^{*} \mathrm{p}<0.05$. 
the critical value of 10 which shows that the model does not have the serious problem of collinearity, and the analysis of the model is acceptable.

Model 1 - 3 in Table 3 shows the influence of psychological capital and organizational support on innovative behavior. Model 2 shows that after introducing the variables of psychological capital and organizational support, the $\beta$ of psychological capital is 0.502 ( $\mathrm{p}<0.001$ ), the $\beta$ of organizational support is $0.413(\mathrm{p}<0.001)$. It shows that both psychological capital and organizational support have a good role in promoting innovative behavior. Model 3 shows that after introducing the interaction term of psychological capital and organizational support, it's found that the interaction term has a significant positive effect on employees' innovative behavior $(\beta=0.054$, $\mathrm{p}<0.05)$. It shows that psychological capital and organizational support have a good interaction on innovative behavior. Figure 1 shows the interaction between the two on innovative behavior in a positive and negative

Table 3. The interaction analysis of organizational support and psychological capital on silence behavior and innovative behavior of technical innovation employees.

\begin{tabular}{|c|c|c|c|c|c|c|}
\hline & \multicolumn{3}{|c|}{ Innovative behavior } & \multicolumn{3}{|c|}{ Silence behavior } \\
\hline & Model1 & Model 2 & Model 3 & Model 4 & Model 5 & Model 6 \\
\hline Constant & 4.105 & 4.071 & 4.054 & 1.659 & 1.657 & 1.678 \\
\hline \multicolumn{7}{|l|}{ Control variable } \\
\hline Gender & -0.010 & 0.043 & 0.046 & -0.073 & -0.086 & -0.095 \\
\hline Educational background & $0.116^{*}$ & 0.069 & 0.069 & -0.079 & -0.063 & -0.063 \\
\hline Work experience & $-0.123^{*}$ & $-0.118^{*}$ & $-0.122^{*}$ & 0.062 & 0.062 & 0.074 \\
\hline \multicolumn{7}{|l|}{ Independent variable } \\
\hline Psychological capital & & $0.502^{* * *}$ & $0.500^{* * *}$ & & $-0.163^{* *}$ & $-0.156^{* *}$ \\
\hline Organizational support & & $0.413^{* * *}$ & $0.418^{* * *}$ & & $-0.096^{*}$ & $-0.111^{*}$ \\
\hline Psychological capital X Organizational support & & & $0.054^{*}$ & & & $-0.161^{* *}$ \\
\hline $\mathrm{R}^{2}$ & 0.032 & 0.601 & 0.604 & 0.018 & 0.065 & 0.090 \\
\hline Adjusted $\mathrm{R}^{2}$ & 0.023 & 0.595 & 0.597 & 0.009 & 0.050 & 0.072 \\
\hline $\mathrm{F}$ & $3.422^{*}$ & $92.061^{* * *}$ & $77.397^{* * *}$ & 1.924 & $4.246^{* *}$ & $5.035^{* * *}$ \\
\hline$\Delta \mathrm{R}^{2}$ & 0.032 & 0.569 & 0.003 & 0.018 & 0.047 & 0.025 \\
\hline $\mathrm{F}$ & $3.422 *$ & $217.769^{* * *}$ & $2.227^{*}$ & 1.924 & $7.605^{* * *}$ & $8.458^{* *}$ \\
\hline
\end{tabular}

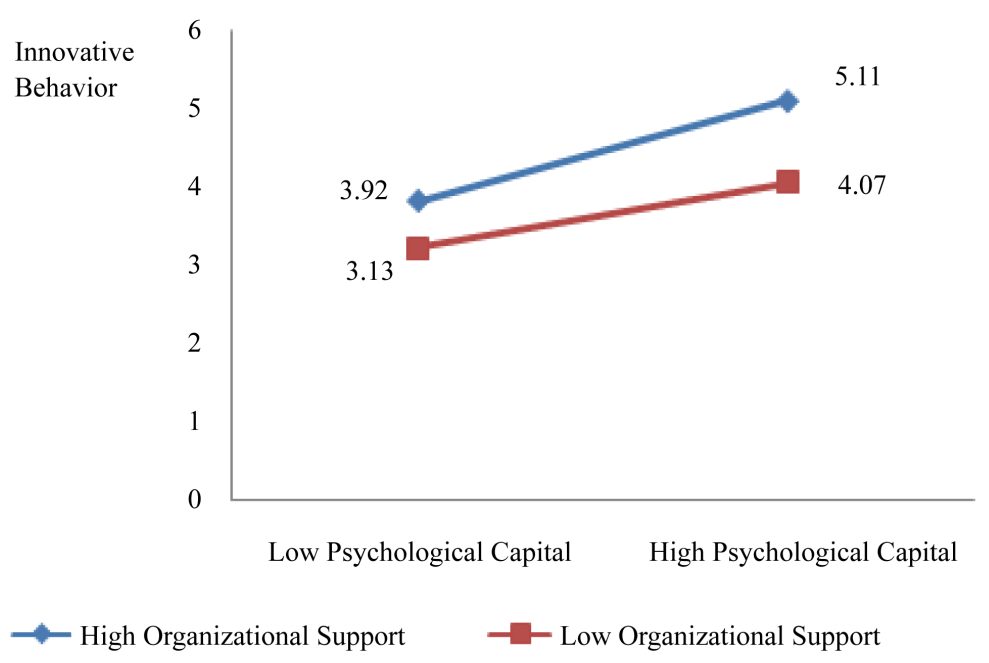

Figure 1. The interaction effect on innovative behavior. 
standard deviation plot, at a high level of psychological capital level, the higher the degree of organizational support, then the innovative behavior will be better. If the level of psychological capital is higher, the level of organizational support is low, contrary the innovation ability of technology innovation staff will be reduced.

Model 4 - 6 shows the influence of psychological capital and organizational support on silence behavior. Model 5 shows that after introducing the variables of psychological capital and organizational support, the $\beta$ of psychological capital is -0.163 ( $p<0.01$ ), the $\beta$ of organizational support is -0.096 ( $\mathrm{p}<0.05$ ). It shows that both psychological capital and organizational support have significant inhibitory effect on employee silence behavior, and the influence of psychological capital is greater than that of organizational support. Model 6 shows that after introducing the interaction term of psychological capital and organizational support and found that the correlation coefficient of the model was $-0.161(\mathrm{p}<0.01)$. It shows that psychological capital and organizational support to some extent on the behavior of employees will also have silent interaction. Figure 2 shows the interaction between the two in the negative and positive standard deviation, the higher the level of psychological capital, the higher the level of organizational support, then silence behavior will get better inhibition. If the level of psychological capital is higher, the level of organizational support is low, the ability of silence will be increased.

\section{Discussion}

The current study validated the effects of psychological capital and organizational support on employees' silence behavior and innovative behavior. It verified the interaction between the psychological capital and organizational support. As for the research results, the article will show more detailed discussion in the following paragraphs. The study showed that the silence behavior of technical innovation employees is connected to their organization and their personal factors. Silence behavior is considered as the obstacle of decision-making quality because of its potential damage to the organization. Employees choose silence as a safe way to keep their jobs. There are some reasons for employees to keep silence, like being afraid of the revenge of their leaders or the tease by their fellows. Good organization support provides a sense of psychological safety and then motivates the psychological capital in this way, therefore the employees are pleasant to provide lot of suggestions actively. Besides, good organization support can improve the loyalty of the employees, make them consider the development of their organization and increase their motivation. For these reason, employees would like to express themselves and provide useful information rather than keep silence. From the perspective of employees, individuals with good psychological capital are more likely to face the problem and then figure out how to solve the problem personally or cooperatively. You need confidence and courage to speak out your idea, which is supported by the study. Organization support and psychological capital have obvious effect on innovational behavior of technical innovation personnel. They have strong concept of innovation and self-efficacy when supported by better organization. They will have superior psychological capital over time. Thus they can get more concept of innovation and solution to a new problem in the course of their work. In the meantime, they are able to introduce their innova-

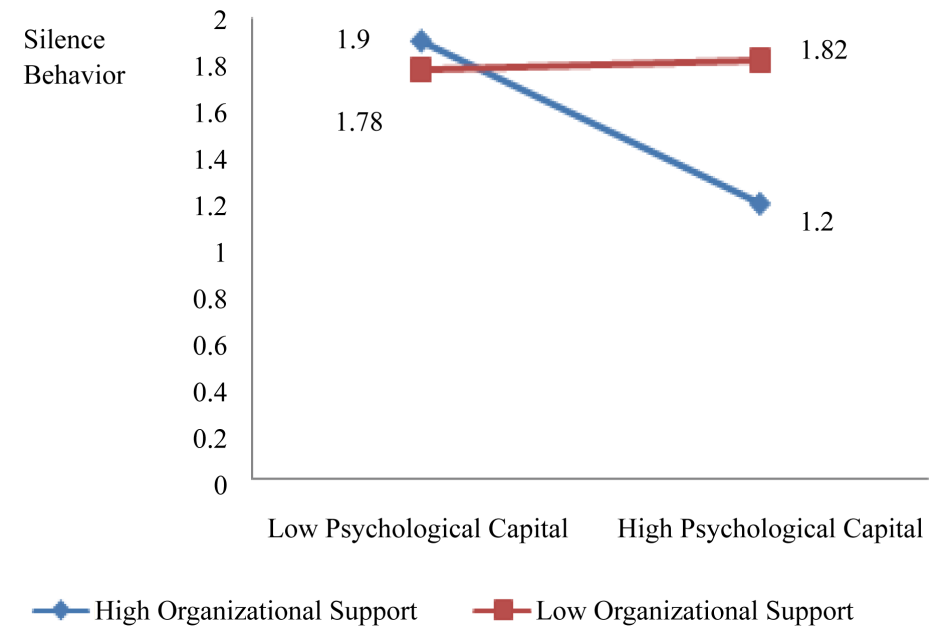

Figure 2. The interaction effect on silence behavior. 
tion ideas to other people or organizations in order to decrease their own or others silence behavior.

\section{Limitations and Prospects}

Due to the limitations of subjective and objective reasons, our research has some drawbacks as follows: Firstly, the distributions of our samples aren't wide enough. We mainly investigate the enterprise sector employees in Beijing and Hebei region. We hope that future research will be able to broaden the coverage of the survey, and to enhance the universality of the research conclusions. Secondly, although this study is conducted to investigate the student class and reduce the concerns of others, as far as possible to reduce the errors, because of the use of self-assessment method, and there are still some deficiencies in the data obtained. In order to better test the basic hypothesis of this research, follow-up study can be considered as far as possible by using self rating and assessment of his combination of way to obtain sample data, and to take proper account of the collection of time series data and using method of longitudinal study to ensure the reliability of the conclusion of the study.

\section{References}

[1] Zhou, J. and George, J.M. (2001) When Job Dissatisfaction Leads to Creativity: Encouraging the Expression of Voice. Academy of Management Journal, 44, 682-696. http://dx.doi.org/10.2307/3069410

[2] Zhao, B., Fu, Q.F. and Li, J.X. (2012) A Study of Psychological Capital’s Impact on Innovative Behavior of Scientific and Technological Personnel: The Moderating Role of Knowledge Work Difficulty. Science of Science and Management of S. \& T., 3, 174-180.

[3] Gu, Y.D. and Peng, J.S. (2008) Independent Innovation Strategy-From the Successful Experience of Innovative Enterprises in Nanjing. Theory Horizon, 5, 64-65.

[4] Pinder, G.G. and Harlos, H.P. (2001) Employee Silence Quiescence and Acquiesce as Responses to Perceived Injustice. Research in Personnel and Human Resource Management, 20, 331-369. http://dx.doi.org/10.1016/S0742-7301(01)20007-3

[5] Zheng, X.T., Shi, J.T. and Zheng, X.S. (2009) The Review of Employee Silence. Economic Management Journal, 3, 173-179.

[6] Li, Z.S. (2009) The Causes and Management Strategies of Employee Silence. Economic Research Guide, 22, 101-102.

[7] Morrison, E.W. and Milliken, F.J. (2000) Organizational Silence: A Barrier to Change and Development in a Pluralistic World. Academy of Management Review, 5, 706-731.

[8] Vakola, M. and Bouradas, D. (2005) Antecedents and Consequences of Organizational Silence: An Empirical Investigation. Employee Relations, 27, 441-458. http://dx.doi.org/10.1108/01425450510611997

[9] Xu, J.Y. (2012) An Empirical Study of Psychological Capital on Employees Silence Behavior. Nanjing Normal University, Nanjing.

[10] Luthans, F. and Youssef, C.M. (2007) Positive Psychological Movement. Organizational Dynamics, 35, 44-53.

[11] Luthans, F., Avolio, B., Walumbwa, F. and Li, W. (2005) The Psychological Capital of Chinese Workers: Exploring the Relationship with Performance. Management and Organization Review, 1, 247-269. http://dx.doi.org/10.1111/j.1740-8784.2005.00011.x

[12] Amabile, T.M., Conti, R., Coon, H., Lazenby, J. and Herron, M. (1996) Assessing the Work Environment for Creativity. The Academy of Management Journal, 39, 1154-1184. http://dx.doi.org/10.2307/256995

[13] Eisenberger, R., Huntington, R. and Hutchison, S. (2002) Organizational Support. Journal of Applied Psychology, 1, 500-507.

[14] Tan, M. (2014) Research on the Relationship between Organizational Support and Employee Innovation Behavior: Influence of Feedback Seeking and Power Distance. Nanjing Normal University, Nanjing.

[15] Chen, H. (2011) Research on the Relationship between Job Demand and Innovative Work Behavior.Technoeconomics \& Management Research, 1, 41-45.

[16] Bowen, F. and Blackmon, K. (2003) Spirals of Silence: The Dynamic Effects of Diversity on Organizational Voice. Journal of Management Studies, 40, 1393-1417. http://dx.doi.org/10.1111/1467-6486.00385

[17] Zhao, B. (2007) Research on the Relationship between Perceived Organizational Support and Organizational Silence. Henan University, Kaifeng.

[18] Edmondson, A.C.(2003) Speaking up in the Operating Room: How Team Leaders Promote in Interdisciplinary Action Teams. Journal of Management Studies, 6, 1419-1452. http://dx.doi.org/10.1111/1467-6486.00386

[19] Gu, Y.D., Zhou, W.L. and Peng, J.S. (2014) How Do Perceived Organizational Support for Creativity Affect Employee 
Creativity Behavior? The Moderating Effect of Achievement Motivation and Job Involvement. Chinese Journal of Management, 4, 548-554.

[20] Zheng, X.T., Ke, J.L., Shi, J.T. and Zheng, X.S. (2008) Survey on Employee Silence and the Impact of Trust on It in China. Acta Psychologica Sinica, 2, 209-217.

\section{Submit or recommend next manuscript to SCIRP and we will provide best service for you:}

Accepting pre-submission inquiries through Email, Facebook, Linkedin, Twitter, etc A wide selection of journals (inclusive of 9 subjects, more than 200 journals)

Providing a 24-hour high-quality service

User-friendly online submission system

Fair and swift peer-review system

Efficient typesetting and proofreading procedure

Display of the result of downloads and visits, as well as the number of cited articles

Maximum dissemination of your research work

Submit your manuscript at: http://papersubmission.scirp.org/ 